\title{
Molecular mechanisms underlying the tumorigenesis of colorectal adenomas: Correlation to activated K-ras oncogene
}

\author{
JAW-YUAN WANG ${ }^{1}$, YUNG-HSIN WANG ${ }^{2}$, SHU-WEN JAO ${ }^{3}$, CHIEN-YU LU ${ }^{4}$, CHAO-HUNG KUO ${ }^{4,5}$, \\ HUANG-MING HU ${ }^{4,5}$, JAN-SING HSIEH ${ }^{1}$, INN-WEN CHONG ${ }^{4,5}$, TIAN-LU CHENG ${ }^{1}$ and SHIU-RU LIN ${ }^{1,6,7}$ \\ ${ }^{1}$ Department of Surgery, Faculty of Medicine, College of Medicine, and Kaohsiung Medical University Hospital, \\ Kaohsiung Medical University; ${ }^{2}$ Graduate Institute of Medicine, College of Medicine, Kaohsiung Medical University, \\ Kaohsiung; ${ }^{3}$ Colon and Rectal Surgery Division, Tri-Service General Hospital, Taipei; ${ }^{4}$ Department of Internal Medicine, \\ Faculty of Medicine, College of Medicine, and Kaohsiung Medical University Hospital, Kaohsiung Medical University, \\ Kaohsiung; ${ }^{5}$ Kaohsiung Municipal Hsiao-Kang Hospital; ${ }^{6}$ Department of Laboratory Medicine, Kaohsiung Medical \\ University Hospital, Kaohsiung Medical University, Kaohsiung; ${ }^{7}$ Graduate Institute of Medical Genetics, \\ College of Medicine, Kaohsiung Medical University, Kaohsiung, Taiwan
}

Received July 28, 2006; Accepted August 25, 2006

\begin{abstract}
Mutations of K-ras gene have been demonstrated in $40-50 \%$ of colorectal cancer and large adenoma $(>1 \mathrm{~cm})$. This study was intended to clarify the correlation between the existence of K-ras oncogene and the pathological features of colorectal adenomas using our recently developed membrane arrays. Moreover, the downstream genes regulated by K-ras oncogene were explored to serve as potential biomarkers in the early diagnosis and risk assessment of patients with colorectal adenoma. Specimens were collected from 70 patients with colorectal adenoma. The alterations of K-ras oncogene were analyzed by direct sequencing and our constructed membrane arrays, respectively. The results of direct sequencing showed that 21 of 70 samples $(30 \%)$ had $\mathrm{K}$-ras gene mutations. The most frequently mutated sites included codons 12,13, 15 and 18. Furthermore, activated $\mathrm{K}$-ras oncogene was identified in 18 of 70 (25.7\%) adenoma by membrane arrays. Statistical analyses showed that the membrane array had the accuracy of $90.0 \%$, sensitivity of $88.9 \%$, and specificity of $90.4 \%$. The frequency of the mutational sites of K-ras gene was located as follows: codon $12,100 \%$ (4/4); codon $13,100 \%$ (4/4); codon $15,75 \%(6 / 8)$; and codon $18,100 \%(2 / 2)$. The analysis of the correlation between the experimental data and pathological characteristics of adenoma showed that activated K-ras oncogenes were significantly associated with the size, number and histology of adenomas (all $\mathrm{P}<0.001$ ). Finally, we found the downstream genes activated by K-ras oncogene, including B-cell CLL/
\end{abstract}

Correspondence to: Professor Shiu-Ru Lin, Graduate Institute of Medical Genetics, College of Medicine, Kaohsiung Medical University, 100 Shin-Chuan 1st Road, Kaohsiung 807, Taiwan E-mail: srlin@ms2.hinet.net

Key words: tumorigenesis, adenoma, K-ras lymphoma 2 (BCL2), Homo sapiens H2A histone family, member Z (H2AFZ), Homo sapiens RAP1B, member of RAS oncogene family (RAP1B), Homo sapiens T-box 19 (TBX19), Homo sapiens E2F transcription factor 4, p107/p130-binding (E2F4) and matrix metallopeptidase 1 (MMP1), of which were overexpressed in most of all examined adenomas. These genes were then suggested to have functions involved in cell growth. The preliminary results indicated that the accuracy of membrane arrays was comparable to conventional DNA sequencing in the detection of activated K-ras oncogenes. Therefore, we propose that activated K-ras oncogene in colorectal adenomas may play an important role in the subsequent colorectal carcinogenesis through a group of K-rasrelated molecular targets.

\section{Introduction}

Colorectal polyps, especially adenomatous polyps, are widely regarded as pre-malignant lesions. The malignant potential of the colorectal adenomas highly correlated with different grades, depending on their size, shape and histological type (1). Generally, intramucosal carcinoma occurs in 5-10\% of colorectal adenomas $(2,3)$. However, those in individuals with family histories of hereditary colorectal adenoma or adenocarcinoma may turn cancerous at a risk of $80 \%$ in lifetime (4). In addition, other reports also suggest an increased risk of developing cancer among colorectal adenoma patients, and the possibility of prophylactic effect of polypectomy against subsequent the development of malignancies (5).

$\mathrm{K}$-ras is a member of the Ras family, the most common oncogenes activated in a wide range of human cancers. Research on Ras oncogene has established mutations of three members of Ras gene family in various human cancers of tissue and organs, including urinary bladder, mammary gland, rectum, kidney, liver, lung, ovary, pancreas, stomach and the hematopoietic system. The frequency of K-ras mutation has been demonstrated to be considerably high in certain types of cancers $(6,7)$, such as in $75 \%$ of pancreatic tumors $(8,9), 45 \%$ 
Table I. Nucleotide sequences of primers used for PCR and DNA sequencing.

\begin{tabular}{llc}
\hline & \multicolumn{1}{c}{ Sequences } & PCR product (bp) \\
\hline Exon 1 & & 131 \\
Forward & 5'-TAATACGACTCACTATAGGGAGATATGTTGAGGGCCCATCTCTC-3' & \\
Reverse & 5'-TCCTAGGTCAGCGCAACCAAAT-3' & \\
Exon 2 & & 148 \\
Forward & 5'-TAATACGACTCACTATAGGGTTCCTACAGGAAGCAAGTAG-3' & \\
Reverse & 5'-CACAAAGAAAGCCCTCCCCA-3' & \\
Sequencing primer & 5'-CCCTATAGTGAGTCGTATTA-3' & \\
\hline
\end{tabular}

of colorectal cancers (9), and $48 \%$ of lung cancer (10). Some studies have proposed that K-ras mutations play a significant role in the onset and progression of colorectal cancer (11). Some others have even pointed out the presence of K-ras mutations in $\sim 70 \%$ of colorectal cancer and $40 \%$ of colonic adenoma $>1.0 \mathrm{~cm}$ in diameter (12). Martinez et al have found that at least one of mutation hotspots such as codons 12 and 13 were mutated in $>18 \%$ of colonic adenoma $>0.5 \mathrm{~cm}$ in diameter (13). Factors such as larger size of adenoma, older age, and lower intake of folic acid have been described to be associated with a higher risk of K-ras gene mutation $(12,14)$. Individuals with colorectal adenoma $>2.0 \mathrm{~cm}$ in diameter or bearing $\mathrm{K}$-ras mutations were reported to have a higher risk of producing recurrent adenoma during the follow-up period (15). Therefore, the mutation of K-ras oncogene is regarded to be a critical step in colorectal tumorigenesis.

According to that described above, K-ras gene mutation does not only occur in the early stage of colorectal cancer, but is involved in the transformation of colorectal adenomas. However, studies analyzing the correlation between the molecular mechanisms underlying colorectal adenomas and activated K-ras oncogene are not available to date. Therefore, the present study was intended to explore the correlation between the molecular determinants of colorectal adenomas and K-ras oncogene. Previously, our laboratory had employed the microarray technique combined with bioinformatics tools to screen all differentially expressed genes after activated $\mathrm{K}$-ras oncogene in human adrenocortical cells transfected with a K-ras mutant, and determined 22 potential gene targets (16). We also constructed a membrane array specific to these twenty-two genes on nylon membrane, and subsequently carried out a clinical trial in which the membrane array was hybridized with samples from various human cancers. The results indicated that the constructed membrane array had a remarkable potential to detect K-ras oncogene in human subjects.

The present study focused on the evaluation of the membrane arrays for determining the presence of activated $\mathrm{K}$-ras and serving as a tool to monitor K-ras gene mutations in colorectal adenomas, in comparison with DNA sequencing. By analyzing K-ras mutations and overexpressed genes activated by K-ras, we anticipated to elucidate the roles of the downstream genes regulated by K-ras oncogene in the prediction of malignant transformation and clinical significance in colorectal adenomas.

\section{Materials and methods}

Specimen collection and DNA extraction. Tissue specimens were obtained from 70 patients with colorectal adenoma at the Kaohsiung Medical University Hospital and Tri-Service General Hospital between March 2004 and February 2005. There were 38 males and 32 females (mean age was 53.1 years, ranging from 40 to 72 years). All tissue samples removed by operation or endoscopic polypectomy, upon acquisition, were frozen instantly in liquid nitrogen, and then stored at $-70^{\circ} \mathrm{C}$ until analysis. Genomic DNA was isolated using proteinase-K (Stratagene, La Jolla, CA, USA) digestion and phenol/ chloroform extraction procedure according to the method by Sambrook et al (17).

Total-RNA extraction and first strand cDNA synthesis. The isolation of total-RNAs from tissue specimens was performed with Isogen $^{\mathrm{TM}}$ (Nippon Gene Co., Ltd., Toyama, Japan) following the modified acidguanidine thiocyanate and phenol/ chloroform extraction method (18). Its concentration was determined spectrophotometrically on the basis of its absorbance at $260 \mathrm{~nm}$. First strand cDNA was synthesized from total-RNA by using a RT-PCR kit. The reverse transcription was carried out in a reaction mixture consisted of $1 \mathrm{X}$ transcription optimized $5 \mathrm{X}$ buffer, $25 \mathrm{mg} / \mathrm{ml}$ oligo(dT) 15 primer, $100 \mathrm{mmol} / \mathrm{l}$ PCR nucleotide mix, $200 \mathrm{mmol} / \mathrm{l} \mathrm{M}-\mathrm{MLV}$ reverse transcriptase, and $0.5 \mathrm{ml}$ of recombinant RNasin ribonuclease inhibitor (Promega Corp., Madison, WI, USA). The reaction mixtures with RNA were incubated at $42^{\circ} \mathrm{C}$ for longer than $2 \mathrm{~h}$, heated to $95^{\circ} \mathrm{C}$ for $5 \mathrm{~min}$, and then stored at $4^{\circ} \mathrm{C}$ until analysis.

Direct sequencing. To identify the mutations of K-ras gene, polymerase chain reaction (PCR) analysis was performed; the oligonucleotide primers for exons 1 and 2 were used, and described in Table I. Briefly, the PCR amplification of DNA samples (20 ng) was carried out in a $50 \mu 1$ reaction volume with a final concentration of $1 \mathrm{X}$ PCR buffer $[10 \mathrm{mmol} / \mathrm{l}$ Tris- $\mathrm{HCl}$ (pH 8.3), $1.5 \mathrm{mmol} / 1 \mathrm{MgCl}_{2}, 50 \mathrm{mmol} / \mathrm{l} \mathrm{KCl}$, and $0.01 \%$ gelatin], $100 \mathrm{mmol} / \mathrm{l}$ each deoxynucleotide triphosphate (Promega), and 5 units ( 1 unit $/ \mu 1$ ) of BIOTOOLS DNA polymerase (Biotechnological \& Medical Laboratories, S.A., Madrid, Spain) for each reaction. The PCR products were purified by the QIAEX II Gel Extraction Kit (Qiagen Inc., Valencia, CA, USA) and then subjected to sequencing using 
Table II. Oligonucleotide probe sequences used for membrane arrays.

GenBank identity/Symbol

Homo sapiens ATPase, $\mathrm{Ca}^{++}$ transporting, cardiac muscle, slow twitch 2/ATP2A2

Homo sapiens ATPase, $\mathrm{H}^{+}$ transporting, lysosomal $21 \mathrm{kDa}$, V0 subunit c"/ATP6V0B

B-cell CLL/lymphoma 2/BCL2

Homo sapiens calmodulin 2/CALM2

Homo sapiens CCAAT/enhancer binding protein, $B / C E B P B$

Homo sapiens collagen, type IV, a 1/COL4A1

Homo sapiens chemokine (C-X-C motif) ligand 11/CXCL11

Homo sapiens chemokine (C-X-C 5'-CCCCATCCTCTATGCTTTCCTTGGAGCCAAATTTAAAACCTCTGCCCAGCAC-3' motif) receptor 4/CXCR4

Homo sapiens cysteine-rich, angiogenic inducer, 61/CYR61

Homo sapiens disheveled, dsh homolog 3 Drosophila)/DVL3

Homo sapiens E2F transcription factor 4, p107/p130-binding/E2F4

Homo sapiens v-ets erythroblastosis virus E26 oncogene homolog 1 (avian)/ETS1

Homo sapiens $\mathrm{H} 2 \mathrm{~A}$ histone family, member Z/H2AFZ

Homo sapiens $\mathrm{L} 1$ cell adhesion molecule/L1CAM

Homo sapiens low density lipoprotein-related protein $1 / \mathrm{LRP} 1$

Matrix metallopeptidase 1/MMP1

Homo sapiens RAP1B, member of RAS oncogene family/RAP1B

Homo sapiens ribosomal protein L30/RPL30

Homo sapiens solute carrier family 25 , member 5/SLC25A5

Homo sapiens secreted phosphoprotein 1/SPP1

Homo sapiens TAF12 RNA polymerase II/TAF12

Homo sapiens T-box 19/TBX19

B-actin

Sequence of probe

5'-ACCCGGACTTTGAAGGCGTGGATTGTGCAATCTTTGAATCCCCATACCCG-3'

5'-CATCGGCCATCGGAACTACCATGCAGGCTACTCCATGTTTGGGGCT-3'

5'-ACAACATCGCCCTGTGGATGACTGAGTACCTGAACCGGCACCTGCACA-3'

5'-GAAGCATTCCGTGTGTTTGATAAGGATGGCAATGGCTATATTAGTGCTGCAGAACTTCG-3'

5'-CCGCCTGCCTTTAAATCCATGGAAGTGGCCAACTTCTACTACGAGGCGGA-3'

5'-GCAAATGTGACTGCCATGGAGTGAAGGGACAAAAGGGTGAAAGAGGCCTC-3'

5'-GTTCAAGGCTTCCCCATGTTCAAAAGAGGACGCTGTCTTTGCATAGGCCC-3'

5'-CAGCAGCCTGAAAAAGGGCAAGAAATGCAGCAAGACCAAGAAATCCCCCG-3'

5'-CGTCACCTTGGCGGACTTTAAGGGCGTTTTGCAGCGACCCAGCTATAAGT-3'

5'-TGAGATCACAGTGAGTGGCGGCCCTGGGACTGATAGCAAGGACAGT-3'

5'-TGGAGCAGCCAGTCATCTTTCAACAGCCTGCAGCGTGTTCCCTCCTATGA-3'

5'-CGTGGAGATGAAGAATTGGATTCTCTCATCAAGGCTACAATTGCTGGTGGTGGTGTC-3'

5'-CCTTCCTGGTGGTGTCCAACACGTCCACCTTCGTGCCCTATGAGATCAAA-3'

5'-ATGCCTGTGAAAACGACCAGTATGGGAAGCCGGGTGGCTGCTCTGACAT-3'

5'-AAGTGACTGGGAAACCAGATGCTGAAACCCTGAAGGTGATGAAGCAGCCC-3'

5'-GGAAGATGAAAGAGTTGTAGGGAAGGAACAAGGTCAAAATCTAGCAAGACAATGGAACAACTGTG-3'

5'-GCTCCAACTCGTTATGAAAAGTGGGAAGTACGTCCTGGGGTACAAGCAGAC-3'

5'-TCTGATGGGATTAAGGGCCTGTACCAAGGCTTTAACGTGTCTGTGCAGGG-3'

5'-GTGGACAGCCAGGACTCCATTGACTCGAACGACTCTGATGATGTAGATGAC-3'

5'-CAGCACCCCTCCACAAGGCTCCATGGCCAATAGTACTGCAGTGGTAAAGA-3'

5'-TCATCTGCTCAATGTGGTGGAGAGTGAGCTTCAGGCAGGGAGGGAAAAAG-3'

5'-TGCATTGTTACAGGAAGTCCCTTGCCATCCTAAAAGCCACCCCACTTCTCTCTAAGGAGA-3' a double-stranded cycle sequencing system (Gibco-BRL, Gaithersburg, MD, USA). The purified products were then sequenced directly with a T7 promoter/IRD800 (LI-COR, Lincoln, NE, USA), which is a T7 promoter primer (Table I) labeled with a heptamethine cyanine dye, or using DNA polymerase incorporating IRD-labeled dATP for sequencing reaction. Upon completion of the sequencing reaction, $4 \mu 1$ of formamide loading buffer was added to the reaction mixture, 
Table III. Schematic representation of membrane array with 22 genes associated with colorectal adenoma, one housekeeping gene, one tuberculosis gene, and three blank controls.

\begin{tabular}{lllllllll}
\hline ATP2A2 & ATP6V0B & BCL2 & CALM2 & CEBPB & MMP1 & COL4A1 & CXCL11 & CXCR4 \\
ATP2A2 & ATP6V0B & BCL2 & CALM2 & CEBPB & MMP1 & COL4A1 & CXCL11 & CXCR4 \\
ATP2A2 & ATP6V0B & BCL2 & CALM2 & CEBPB & MMP1 & COL4A1 & CXCL11 & CXCR4 \\
CYR61 & DVL3 & E2F4 & ETS1 & H2AFZ & L1CAM & LRP1 & RAP1B & RPL30 \\
CYR61 & DVL3 & E2F4 & ETS1 & H2AFZ & L1CAM & LRP1 & RAP1B & RPL30 \\
CYR61 & DVL3 & E2F4 & ETS1 & H2AFZ & L1CAM & LRP1 & RAP1B & RPL30 \\
SLC25A5 & SPP1 & TAF12 & TBX19 & TB & Blank & Blank & Blank & ß-actin \\
SLC25A5 & SPP1 & TAF12 & TBX19 & TB & Blank & Blank & Blank & B-actin \\
SLC25A5 & SPP1 & TAF12 & TBX19 & TB & Blank & Blank & Blank & B-actin \\
\hline
\end{tabular}

The symbols represent the genes spotted onto membrane arrays, their GenBank identities are listed in Table II.

(A)



(B)

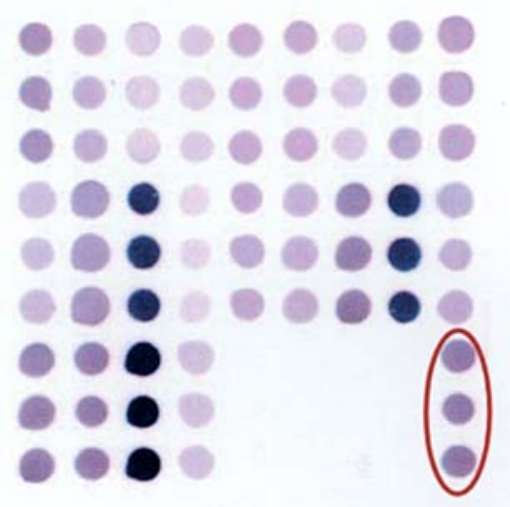

Figure 1. Differential gene expression patterns in the colorectal adenoma patients analyzed by constructed membrane arrays in the detection of activated K-ras oncogene. Fourteen of a triplicate set of 22 candidate genes were overexpressed in one colorectal adenoma patient, whereas only one gene was overexpressed in another colorectal adenoma patient. Thus, the results for the former and the latter colorectal adenoma patients were interpreted as positive and negative, respectively. The genes within red circle of each image represent $\beta$-actin (positive control).

the sample heated to $95^{\circ} \mathrm{C}$ for 5 min, snap cooled and loaded onto the sequencing gel.

An automated DNA electrophoresis system (Model 4200; LI-COR) with a laser diode emitting at $785 \mathrm{~nm}$ and fluorescence detection between 815 and $835 \mathrm{~nm}$ was used to detect and analyze the sequencing ladder. Electrophoresis was performed on a $41 \mathrm{~cm} \times 25 \mathrm{~cm} \times 0.2 \mathrm{~mm}$ gel consisting of $6 \%$ Long Ranger gel matrix (AT Biochem; Malvern, PA, USA) with $7 \mathrm{M}$ urea and a running buffer consisting of $133 \mathrm{mM}$ Tris base, $44 \mathrm{mM}$ boric acid and $2.5 \mathrm{mM}$ EDTA, $\mathrm{pH} 9.0$ at $50^{\circ} \mathrm{C}$. From each sequencing reaction, $1.5 \mu 1$ of the sample was loaded on each lane. Following the loading of samples, electrophoresis was carried out at a constant voltage of $2000 \mathrm{~V}$ with the gel heated to $50^{\circ} \mathrm{C}$. Data collection and image analysis was performed by an IBM486 (Model 90) using the Base Image IR software supplied with the model 4200 DNA sequencer.

Oligonucleotide membrane array preparation. The procedure for the design and preparation of membrane arrays was according to our previously described method $(16,19)$. Using a version of OMP (Oligonucleotide Modeling Platform, DNA
Software, Ann Arbor, MI, USA), DNA software tailored to probe sequences for each target are designed and a single best candidate is selected, with $\beta$-actin served as an internal control (Table II). The newly synthesized oligonucleotide fragments were dissolved in DI-water to a concentration of $20 \mathrm{mM}$ and then applied to a BioJet Plus 3000 nanoliter dispense system (BioDot Inc., Irvine, CA, USA), which blotted sequentially the 51 target DNAs (Table I), 1 housekeeping gene (ß-actin), and 1 tuberculosis gene (TB; $50 \mathrm{nl}$ per spot and $1.5 \mathrm{~mm}$ between spots) on Nytran ${ }^{\circledR}$ SuperCharge nylon membrane (Schleicher and Schuell, Dassel, Germany) and then cross-linked to the membrane using a UV Stratalinker 1800 (Stratagene) in triplicate. Each spot consists of $20 \mathrm{ng}$ of PCR-amplified DNA derived from sequence-verified cDNA clones. DMSO was also dispensed onto the membrane as a blank control (Table III, Fig. 1).

Preparation of digoxigenin-labeled cDNA targets and hybridization. First-strand cDNA targets for hybridization were produced by using SuperScript II reverse transcriptase (Gibco-BRL) in the presence of digoxigenin (DIG)-labeled 
Table IV. The correlation between the membrane arrays and DNA sequencing for the detection of activated K-ras oncogene in colorectal adenoma patients.

\begin{tabular}{lrrr}
\hline & \multicolumn{2}{c}{ Membrane-array } & \\
& Positive & Negative & P-value \\
\hline Direct sequencing & & & \\
Positive & 16 & 2 & $<0.001$ \\
Negative & 5 & 47 & \\
\hline
\end{tabular}

Sensitivity: $88.9 \%$ (95\% CI, 78.2-99.6\%); specificity: $90.4 \%$ (95\% CI, 80.3-100.4\%); positive predictive value: $76.2 \%$ (95\% CI, 61.7-90.7\%); negative predictive value: $97.9 \%$ (95\% CI, 89.2-102.7\%); and accuracy: $90.0 \%$.

UTP (Roche Diagnostics GmbH, Penzberg, Germany). After procedures of prehybridization and blocking, the membrane arrays were subjected to hybridization. The lifts were covered with the ExpressHyb Hybridization Solution (BD Biosciences, Palo Alto, CA, USA) containing DIG-11-UTP-labeled cDNA probes, and then incubated with an alkaline phosphataseconjugated anti-digoxigenin antibody (Roche Diagnostics). For hybridization, the arrays were incubated at $42^{\circ} \mathrm{C}$ for $12 \mathrm{~h}$ in a humid chamber. After washing, the arrays were then exposed to light that excites the light. For signal detection, the membrane arrays were incubated for $15 \mathrm{~min}$ in a chromogen solution containing nitroblue-tetrazolium and 5-bromo-4chloro3-indolyl-phosphate (NBT/BCIP). The hybridized arrays were then scanned with an Epson Perfection 1670 flat bed scanner (Seiko Epson Corp., Nagano-ken, Japan). Subsequent quantification analysis of each spot's intensity was carried out by using AlphaEase ${ }^{\circledR}$ FC software (Alpha Innotech Corp., San Leandro, CA, USA). Spots consistently differing by a factor of two or more were considered as differentially expressed.

Statistical analysis. The data were analyzed using the Statistical Package for the Social Sciences Ver. 11.5 software (SPSS Inc., Chicago, IL, USA). The $\chi^{2}$ test with Yates' correction and the Fisher exact test were used to compare pathological parameters between patients with K-ras mutants and with wildtype. A P-value $<0.05$ was considered to be statistically significant.

\section{Results}

The results of direct sequencing showed that of 70 colorectal adenomas, 18 (25.7\%) had K-ras gene mutations. These mutations were most frequently localized at codons 12,13 , 15 and 18. The criterion for a positive result of the membrane array described in the previous study was determined by using the ROC (receiver-operating characteristic) curve analysis (16): for all 22 target genes, a cut-off value for the number of 11 positive genes was used, where the sensitivity was $88.9 \%$ (95\% CI, 78.2-99.6\%), and the specificity $90.4 \%$ (95\% CI, $80.3-100.4 \%$ ) for membrane arrays in the detection of activated K-ras oncogene (Table IV). Of 70 colorectal
Table V. The distribution and detection frequency of K-ras mutational site identified by DNA sequencing in 18 colorectal adenoma tissues further analyzed by membrane arrays.

\begin{tabular}{lcc}
\hline $\begin{array}{l}\text { Mutational } \\
\text { sites }\end{array}$ & $\begin{array}{c}\text { Number detected by } \\
\text { DNA sequencing (\%) }\end{array}$ & $\begin{array}{l}\text { Simultaneously positive } \\
\text { in membrane arrays (\%) }\end{array}$ \\
\hline Codon 12 & $4(22.2)$ & $4(100)$ \\
Codon 13 & $4(22.2)$ & $4(100)$ \\
Codon 15 & $8(44.4)$ & $6(75)$ \\
Codon 18 & $2(11.2)$ & $2(100)$ \\
\hline
\end{tabular}

adenomas, $21(30 \%)$ were positive for the membrane array analysis, while $49(70 \%)$ were negative. The results showed that 16 of 21 membrane array-positive specimens was subsequently considered as K-ras mutations by direct sequencing, while 47 of 49 membrane array-negative samples was regarded as no K-ras gene mutations by direct sequencing. In addition, there were 5 false positives and 2 false negatives, and a remarkable accuracy of $90 \%$ in this analysis.

Eighteen specimens with K-ras gene mutations by direct sequencing were further analyzed for mutational sites. Four mutation hotspots were thus found, including codons 12, 13, 15 and 18, with the corresponding mutation frequencies of $22.2,22.2,44.5$ and $11.1 \%$, respectively (Table V). In addition, most adenomas with K-ras mutations at codon 12,13 or 15 had tubulovillous or villous architecture in morphology, multiple in number and a larger tumor size $(>1.5 \mathrm{~cm})$, while those with K-ras codon 18 mutation were mostly tubular, single and smaller $(<1.5 \mathrm{~cm})$ (data not shown). The correlation between mutational sites and results of membrane array was explored. It was revealed that $100 \%$ (4/4) of samples with K-ras codon 12 mutation, (4/4) of samples with K-ras codon 13 mutation, 75\% (6/8) of samples with K-ras codon 15 mutation, and $100 \%$ (2/2) of sample with K-ras codon 18 mutation were interpreted as positive using the membrane array analysis.

Pathological characteristics such as size, number, and histology of adenomas were then analyzed for their correlation with presence of activated K-ras oncogene by membrane arrays (Table VI). It was revealed that the positive rates of activated K-ras oncogene in patients with adenomas $>1.5 \mathrm{~cm}$ in diameter or multiple adenomas was significantly higher than those in patients with adenomas $<1.5 \mathrm{~cm}$ in diameter or single adenoma (both $\mathrm{P}<0.001$ ). In histological analysis, the activated K-ras oncogene was found more often in tubulovillous and villous adenomas, whereas wild-type K-ras was observed more frequently in tubular adenomas $(\mathrm{P}<0.001)$.

When analyzing the most important up-regulated genes activated by K-ras in colorectal adenomas, we found that six genes including B-cell CLL/lymphoma 2 (BCL2), Homo sapiens $\mathrm{H} 2 \mathrm{~A}$ histone family, member $\mathrm{Z}$ (H2AFZ), Homo sapiens RAP1B, member of RAS oncogene family (RAP1B), Homo sapiens T-box 19 (TBX19), Homo sapiens E2F transcription factor 4, p107/p130-binding (E2F4) and matrix metallopeptidase 1 (MMP1), were prominently overexpressed. The analysis of pathological features showed that 
Table VI. The correlation between the membrane arrays for the detection of activated K-ras oncogene and pathological features in colorectal adenoma patients.

\begin{tabular}{|c|c|c|c|}
\hline \multirow[b]{2}{*}{ Variables } & \multicolumn{2}{|c|}{ Membrane arrays } & \multirow[b]{2}{*}{ P-value } \\
\hline & $\begin{array}{c}\text { Positive }(\%) \\
(\mathrm{N}=21)\end{array}$ & $\begin{array}{c}\text { Negative (\%) } \\
(\mathrm{N}=49)\end{array}$ & \\
\hline \multicolumn{4}{|l|}{ Maximum size } \\
\hline$<1.5 \mathrm{~cm}$ & $4 \quad(19)$ & $38(77.6)$ & $<0.001$ \\
\hline$\geq 1.5 \mathrm{~cm}$ & $17 \quad(81)$ & $11(22.4)$ & \\
\hline \multicolumn{4}{|l|}{ Number } \\
\hline Single & $2(9.5)$ & $37(75.5)$ & $<0.001$ \\
\hline Multiple & $19(90.5)$ & $12(24.5)$ & \\
\hline \multicolumn{4}{|l|}{ Histology } \\
\hline Tubular & $3(14.3)$ & $35(71.4)$ & $<0.001$ \\
\hline Tubulovillous & $10(47.6)$ & $12(24.5)$ & \\
\hline Villous & $8(38.1)$ & $2(4.1)$ & \\
\hline
\end{tabular}

the overexpression of these 6 genes were more frequently encountered in larger adenoma $(>1.5 \mathrm{~cm})$, multiple adenomas, and tubulovillous or villous types (Table VII).

\section{Discussion}

In the present study, we used membrane arrays detecting downstream genes activated by K-ras oncogene to indicate the activation of K-ras oncogene. A positive result in the membrane array analysis proposed the existence of activated $\mathrm{K}$-ras oncogene. The comparison between data of membrane arrays and direct sequencing showed the membrane array method had higher specificity, sensitivity and accuracy for the detection of K-ras activation. The statistical analysis demonstrated the consistence of both methods. This finding also served as evidence that the membrane array was feasible to detect activated $\mathrm{K}$-ras oncogene in human tissue, in addition to blood samples (16). The conventional mean for analyzing the oncogenicity of K-ras requires DNA sequencing (20). DNA sequencing provides information on gene mutation sites, but it is relatively difficult to determinate in a series of complicated protein activity assays to determine whether or not K-ras is activated (21). Using the membrane array analysis, we could effectively carry out the detection of K-ras oncogene activation with the advantage of both time-saving and costeffectiveness, thus suggesting that this convenient method has potential for clinical practice in the future.

Moreover, direct sequencing revealed that the mutation hotspots of K-ras gene in colorectal adenomas were codons $12,13,15$ and 18 (22-24). This finding was consistent with the K-ras mutation hotspots in Taiwanese colorectal cancer patients reported previously (24). Our observations suggest that K-ras gene in both colorectal cancer and colon adenoma in Taiwanese patients are frequently mutated at codon 15 and to a lesser degree at codons 12,13 and 61 as documented in the literature (25). The possible explanation might include the exposure to certain carcinogenic agents in different environments favorable for mutations at specific mutation sites (26).

Furthermore, we have demonstrated that the incidence of activated K-ras oncogene is significantly associated with the size, number and pathological types of colorectal adenomas. Recent studies have also found that K-ras gene mutations are apt to take place in more advanced histology and progression of adenomas $(27,28)$. Cells with activated K-ras oncogene are characterized by traits related to cancer, such as lack of contact inhibition, and resistance to apoptosis (29-31). It is reasonable to conjecture that larger or multiple or those of pathologically more advanced adenomas are at relatively high risks of activated K-ras mutation, and may cause subsequent transformation. Consequently, it is clear that $\mathrm{K}$ ras oncogene plays an important role in deciding the fate of colorectal adenomas. The literature has also showed some association between mutation sites of K-ras gene and the

Table VII. The distribution between the six most frequently overexpressed genes in membrane arrays and pathological features in 18 colorectal adenoma patients with activated K-ras oncogene.

\begin{tabular}{|c|c|c|c|c|c|c|c|c|c|c|c|c|}
\hline & \multicolumn{2}{|c|}{ BCL2 } & \multicolumn{2}{|c|}{ H2AFZ } & \multicolumn{2}{|c|}{ RAP1B } & \multicolumn{2}{|c|}{ TBX19 } & \multicolumn{2}{|c|}{ E2F4 } & \multicolumn{2}{|c|}{ MMP1 } \\
\hline & + & - & + & - & + & - & + & - & + & - & + & - \\
\hline \multicolumn{13}{|l|}{ Maximum size } \\
\hline$<1.5 \mathrm{~cm}$ & 3 & 0 & 2 & 1 & 3 & 0 & 2 & 1 & 2 & 1 & 2 & 1 \\
\hline$\geq 1.5 \mathrm{~cm}$ & 15 & 0 & 15 & 0 & 15 & 0 & 15 & 0 & 14 & 1 & 14 & 1 \\
\hline \multicolumn{13}{|l|}{ Number } \\
\hline Single & 2 & 0 & 1 & 1 & 2 & 0 & 1 & 1 & 1 & 1 & 1 & 1 \\
\hline Multiple & 16 & 0 & 16 & 0 & 16 & 0 & 16 & 0 & 15 & 1 & 15 & 1 \\
\hline \multicolumn{13}{|l|}{ Histology } \\
\hline Tubular & 3 & 0 & 2 & 1 & 3 & 0 & 3 & 0 & 3 & 1 & 2 & 1 \\
\hline Tubulovillous & 9 & 0 & 9 & 0 & 9 & 0 & 9 & 0 & 9 & 0 & 8 & 1 \\
\hline Villous & 6 & 0 & 6 & 0 & 6 & 0 & 6 & 0 & 4 & 1 & 5 & 0 \\
\hline
\end{tabular}


degree of cell transformation (32-34). For instance, cells with $\mathrm{K}$-ras codon 12 mutation have an increased transforming capacity (35) and reduced apoptosis $(36,37)$, compared to cells with K-ras codon 13 mutation; codon 12 mutation is frequently present in metastatic colorectal cancer $(32,38)$, while codon 13 mutation is found in most non-invasive cancers. The results indicate that K-ras codon 12 mutation may make significant contribution to cell transformation and malignancy. Consistent with previous investigations, we have also provided evidence that K-ras codon 12 mutation were detectable in larger or multiple adenomas or those of pathologically advanced types. However, the consequences of K-ras gene mutations at codon 15 and 18, however, remain to be clarified.

The gene expression analysis showed that K-ras oncogene regulated downstream genes including BCL2, H2AFZ, RAP1B, TBX19, E2F4 and MMP1 were highly expressed in most colorectal adenoma samples. These genes were known to prominently participate in cell growth and differentiation (39-45). Therefore, we propose that these six genes may significantly contribute to the mechanism underlying tumorigenesis of colorectal adenomas, and thereby can serve as potential markers indicative of the degree of advanced histology. A careful follow-up is advisable for colorectal adenoma patients with these overexpressed genes.

In summary, our constructed membrane array specialized for the detection of activated K-ras oncogene seems to be useful, reliable, and convenient; moreover, it affords an additional route to elucidate the molecular pathway of K-ras gene activation in colorectal tumorigenesis. Further prospective studies will be required to determine whether the presence of activated $\mathrm{K}$-ras oncogene is associated with clinical progression, and recurrence of colorectal adenomas will need the enrollment of a larger patient population and serial follow-up.

\section{Acknowledgements}

The authors are grateful for the generous research support provided by Dr T.F. Chen and O.L. Hsu (the founders of Sunrider International), through Give2Asia Foundation, to Kaohsiung Medical University Education and Development Fund.

\section{References}

1. Jass JR: Serrated adenoma and colorectal cancer. J Pathol 187: 499-502, 1999.

2. Longacre TA and Fenoglio-Preiser CM: Mixed hyperplastic adenomatous polyps/serrated adenomas. A distinct form of colorectal neoplasia. Am J Surg Pathol 14: 524-537, 1990.

3. Ladas SD, Kitsanta P, Triantafyllou K, Tzathas C, Spiliadi C and Raptis SA: Cell turnover of serrated adenomas. J Pathol 206: 62-67, 2005.

4. Abdel-Rahman WM, Mecklin JP and Peltomaki P: The genetics of HNPCC: Application to diagnosis and screening. Crit Rev Oncol Hematol 58: 208-220, 2006.

5. Murakami R, Tsukuma H, Kanamori S, Imanishi K, Otani T, Nakanishi K, Fujimoto I and Oshima A: Natural history of colorectal polyps and the effect of polypectomy on occurrence of subsequent cancer. Int J Cancer 46: 159-164, 1990.

6. Risques RA, Moreno V, Ribas M, Marcuello E, Capella G and Peinado MA: Genetic pathways and genome-wide determinants of clinical outcome in colorectal cancer. Cancer Res 63: 7206-7214, 2003.
7. Wu JT, Kakar S, Nelson RL, Mihalov ML, Hayward B, Gilbert PB and Ghosh L: Prognostic significance of DCC and p27Kip1 in colorectal cancer. Appl Immunohistochem Mol Morphol 13: 45-54, 2005

8. Sawabu N, Watanabe H, Yamaguchi Y, Ohtsubo K and Motoo Y: Serum tumor markers and molecular biological diagnosis in pancreatic cancer. Pancreas 28: 263-267, 2004.

9. Wang JY, Hsieh JS, Chang MY, Huang TJ, Chen FM, Cheng TL, Alexandersen K, Huang YS, Tzou WS and Lin SR: Molecular detection of APC, K-ras and p53 mutations in the serum of colorectal cancer patients as circulating biomarkers. World J Surg 28: 721-726, 2004.

10. Sugio K, Osaki T, Oyama T, Takenoyama M, Hanagiri T, Morita M, Yamazaki K, Nagashima A, Nakahashi H, Maehara Y and Yasumoto K: Genetic alteration in carcinoid tumors of the lung. Ann Thorac Cardiovasc Surg 9: 149-154, 2003.

11. Stenzel A, Semczuk A, Rozynskal K, Jakowicki J and Wojcierowski J: 'Low-risk' and 'high-risk' HPV-infection and K-ras gene point mutations in human cervical cancer: a study of 31 cases. Pathol Res Pract 197: 597-603, 2001.

12. Giacosa A, Frascio F and Munizzi F: Epidemiology of colorectal polyps. Tech Coloproctol 8 (Suppl. 2): S243-S247, 2004.

13. Martinez ME, Maltzman T, Marshall JR, Einspahr J, Reid ME, Sampliner R, Ahnen DJ, Hamilton SR and Alberts DS: Risk factors for Ki-ras protooncogene mutation in sporadic colorectal adenomas. Cancer Res 59: 5181-5185, 1999.

14. Neugut AI, Jacobson JS and De Vivo I: Epidemiology of colorectal adenomatous polyps. Cancer Epidemiol Biomarkers Prev 2: 159-176, 1993.

15. Nusko G, Sachse R, Mansmann U, Wittekind C and Hahn EG: $\mathrm{K}-R A S-2$ gene mutations as predictors of metachronous colorectal adenomas. Scand J Gastroenterol 32: 1035-1041, 1997.

16. Chen YF, Wang JY, Wu CH, Chen FM, Cheng TL and Lin SR: Detection of circulating cancer cells with K-ras oncogene using membrane array. Cancer Lett 229: 115-122, 2005.

17. Sambrook J, Fritsch EF and Maniatis T: Molecular cloning: a laboratory manual. (eds). Cold Spring Harbor Laboratory, New York, pp6.22-6.34, 1989.

18. Chomczynski P and Sacchi N: Single-step method of RNA isolation by acid guanidinium thiocyanate-phenol-chloroform extraction. Anal Biochem 162: 156-159, 1987.

19. Wang JY, Yeh CS, Chen YF, Wu CH, Hsieh JS, Huang TJ, Huang SY and Lin SR: Development and evaluation of a colorimetric membrane-array method for the detection of circulating tumor cells in the peripheral blood of Taiwanese patients with colorectal cancer. Int J Mol Med 17: 737-747, 2006.

20. Tada M, Omata M and Ohto M: Clinical application of ras gene mutation for diagnosis of pancreatic adenocarcinoma. Gastroenterology 100: 233-238, 1991.

21. Schramm K, Krause K, Bittroff-Leben A, Goldin-Lang P, Thiel E and Kreuser ED: Activated K-ras is involved in regulation of integrin expression in human colon carcinoma cells. Int J Cancer 87: 155-164, 2000.

22. Forrester K, Almoguera C, Han K, Grizzle WE and Perucho M: Detection of high incidence of K-ras oncogenes during human colon tumorigenesis. Nature 327: 298-303, 1987.

23. Hayakumo T, Azuma T, Nakajima M, Yasuda K, Cho E, Mukai H, Mizuma Y, Ashihara T, Mizuno S and Hirano S: Prevalence of K-ras gene mutations in human colorectal cancers. Nippon Shokakibyo Gakkai Zasshi 88: 1539-1544, 1991

24. Wang JY, Hsieh JS, Chen FM, Yeh CS, Huang TJ and Lin SR: High frequency of activated K-ras codon 15 mutant in colorectal carcinomas from Taiwanese patients. Int J Cancer 107: 387-393, 2003.

25. Bos JL, Fearon ER, Hamilton SR, Verlaan-de Vries M, van Boom JH, van der Eb AJ and Vogelstein B: Prevalence of K-ras mutations in human colorectal cancer. Nature 327: 293-297, 1987.

26. Brown K, Buchmann A and Balmain A: Carcinogen-induced mutations in the mouse c-Ha-ras gene provide evidence of multiple pathways for tumor progression. Proc Natl Acad Sci USA 87: 538-542, 1990.

27. Maltzman T, Knoll K, Martinez ME, Byers T, Stevens BR, Marshall JR, Reid ME, Einspahr J, Hart N, Bhattacharyya AK, Kramer CB, Sampliner R, Alberts DS and Ahnen DJ: Ki-ras proto-oncogene mutations in sporadic colorectal adenomas: relationship to histologic and clinical characteristics. Gastroenterology 121: 302-309, 2001.

28. Barry EL, Baron JA, Grau MV, Wallace K and Haile RW: K-ras mutations in incident sporadic colorectal adenomas. Cancer 106: 1036-1040, 2006. 
29. Pawlak G and Helfman DM: Cytoskeletal changes in cell transformation and tumorigenesis. Curr Opin Genet Dev 11: 41-47, 2001.

30. Giehl K: Oncogenic Ras in tumour progression and metastasis. Biol Chem 386: 193-205, 2005.

31. Hayashi N, Sugai S, Ito I, Nakamori S, Ogawa M and Nakamura Y: Ethnic difference in the pattern of K-ras oncogene mutations in human colorectal cancers. Hum Mutat 8: 258-261, 1996.

32. Marshall MS: Ras target proteins in eukaryotic cells. FASEB J 9: 1311-1318, 1995

33. Finkelstein SD, Sayegh R, Bakker A and Swalsky P: Determination of tumor aggressiveness in colorectal cancer by K-ras-2 analysis. Arch Surg 128: 526-531, 1993.

34. White MA, Nicolette C, Minden A, Polverino A, van Aelst L, Karin M and Wigler MH: Multiple Ras functions can contribute to mammalian cell transformation. Cell 80: 533-541, 1995.

35. Bos JL, Toksoz D, Marshall CJ, Verlaan-de Vries M, Veeneman GH, van der Eb AJ, van Boom JH, Janssen JW and Steenvoorden AC: Amino-acid substitutions at codon 13 of the $\mathrm{N}$-ras oncogene in human acute myeloid leukaemia. Nature 315: 726-730, 1985.

36. Ward RL, Todd AV, Santiago F, O'Connor T and Hawkins NJ: Activation of the K-ras oncogene in colorectal neoplasms is associated with decreased apoptosis. Cancer 79: 1106-1113, 1997.

37. Guerrero S, Casanova I, Farre L, Mazo A, Capella G and Mangues R: K-ras codon 12 mutation induces higher level of resistance to apoptosis and predisposition to anchorageindependent growth than codon 13 mutation or proto-oncogene overexpression. Cancer Res 60: 6750-6756, 2000.

38. Finkelstein SD, Sayegh R, Christensen S and Swalsky PA: Genotypic classification of colorectal adenocarcinoma. Biologic behavior correlates with K-ras-2 mutation type. Cancer 71: 3827-3838, 1993.
39. Termuhlen PM, Sweeney-Gotsch BM, Berman RS, Ellis LM, Bucana C, Shen Y, Cleary KR and McConkey DJ: Increased apoptosis in metastatic human colonic adenocarcinomas. Cancer Biol Ther 1: 58-63, 2002.

40. Bedi A, Pasricha PJ, Akhtar AJ, Barber JP, Bedi GC, Giardiello FM, Zehnbauer BA, Hamilton SR and Jones RJ: Inhibition of apoptosis during development of colorectal cancer. Cancer Res 55: 1811-1816, 1995.

41. Farris SD, Rubio ED, Moon JJ, Gombert WM, Nelson BH and Krumm A: Transcription-induced chromatin remodeling at the c-myc gene involves the local exchange of histone H2A.Z. J Biol Chem 280: 25298-25303, 2005.

42. Mitra RS, Zhang Z, Henson BS, Kurnit DM, Carey TE and D'Silva NJ: Rap1A and rap1B ras-family proteins are prominently expressed in the nucleus of squamous carcinomas: nuclear translocation of GTP-bound active form. Oncogene 22: 6243-6256, 2003.

43. Balciunaite E, Spektor A, Lents NH, Cam H, Te Riele H, Scime A, Rudnicki MA, Young R and Dynlacht BD: Pocket protein complexes are recruited to distinct targets in quiescent and proliferating cells. Mol Cell Biol 25: 8166-8178, 2005.

44. Moriyama H, Sasamoto H, Kambara T, Matsubara N, Ikeda M, Baba S, Meltzer SJ, Lynch HT, Shimizu K and Tanaka N: E2F-4 mutation in hereditary non-polyposis colorectal cancer. J Exp Clin Cancer Res 21: 185-189, 2002.

45. Poola I, De Witty RL, Marshalleck JJ, Bhatnagar R, Abraham J and Leffall LD: Identification of MMP-1 as a putative breast cancer predictive marker by global gene expression analysis. Nat Med 11: 481-483, 2005. 